\title{
CFD Modeling of Helium Pressurant Effects on Cryogenic Tank Pressure Rise Rates in Normal Gravity
}

\author{
Gary Grayson*, Alfredo Lopez ${ }^{\dagger}$ and Frank Chandler \\ The Boeing Company, Huntington Beach, California 92467 \\ Leon Hastings ${ }^{\S}$ \\ Alpha Technology, Inc., Huntsville Alabama 35812 \\ Ali Hedayat ${ }^{* *}$ \\ NASA Marshall Space Flight Center, Huntsville, Alabama 35812 \\ and \\ James Brethour ${ }^{\dagger \dagger}$ \\ Flow Science, Inc., Santa Fe, New Mexico 87505
}

\begin{abstract}
A recently developed computational fluid dynamics modeling capability for cryogenic tanks is used to simulate both self-pressurization from external heating and also depressurization from thermodynamic vent operation. Axisymmetric models using a modified version of the commercially available FLOW-3D software are used to simulate actual physical tests. The models assume an incompressible liquid phase with density that is a function of temperature only. A fully compressible formulation is used for the ullage gas mixture that contains both condensable vapor and a noncondensable gas component. The tests, conducted at the NASA Marshall Space Flight Center, include both liquid hydrogen and nitrogen in tanks with ullage gas mixtures of each liquid's vapor and helium. Pressure and temperature predictions from the model are compared to sensor measurements from the tests and a good agreement is achieved. This further establishes the accuracy of the developed FLOW-3D based modeling approach for cryogenic systems.
\end{abstract}

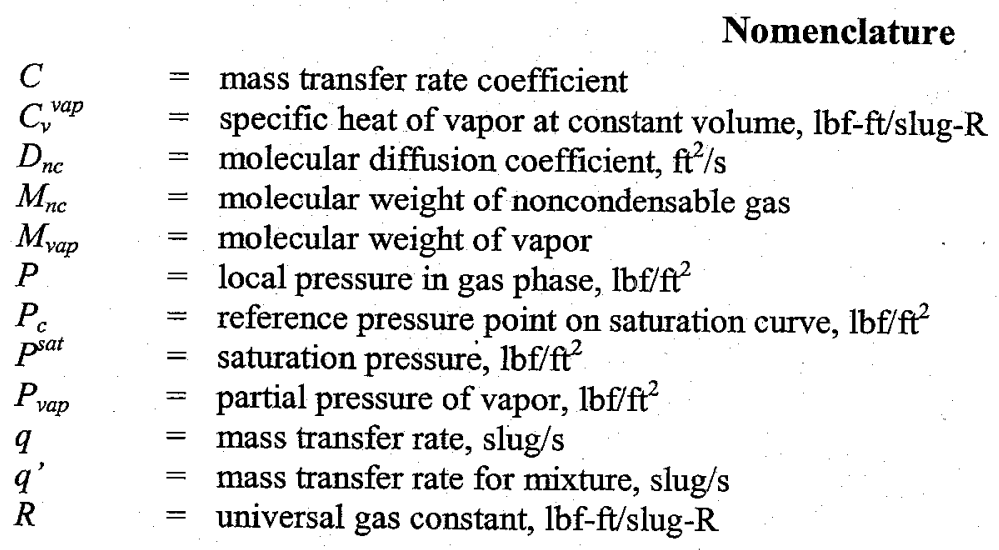

\footnotetext{
*Associate Technical Fellow, Propulsion \& Cryogenic Tech., 5301 Bolsa Ave/H012-2B201, Senior Member

$\dagger$ Associate Engineer/Scientist, Propulsion \& Cryogenic Technologies, 5301 Bolsa, Ave/H012-2B201

$\ddagger$ Director, Propulsion \& Cryogenic Technologies, 5301 Bolsa Ave/H012-2B201, Associate Fellow

§ CFM Technology Consultant, Propulsion Systems Dept. ER23/ATI, Associate Member

** Aerospace Engineer, Engineering Directorate, Mail Stop ER23, Senior Member

${ }^{\dagger+}$ Scientist, 683 Harkle Road, Suite A
} 


$\begin{array}{ll}\bar{R}^{\prime} & =\text { gas constant for mixture, lbf-ft/slug- } \mathrm{R} \\ t & =\text { time, } \mathrm{s} \\ T & =\text { local temperature of liquid-gas interface, } \mathrm{R} \\ T_{c} & =\text { reference temperature point on saturation curve, } \mathrm{R} \\ v & =\text { local velocity of gas mixture, } \mathrm{ft} / \mathrm{s} \\ \Delta H_{v} & =\text { latent heat of vaporization, } \mathrm{lbf}-\mathrm{ft} / \mathrm{slug} \\ \gamma & =\text { specific heat ratio } \\ \rho_{g} & =\text { density of gas mixture, slug } / \mathrm{ft}^{3} \\ \rho_{n c} & =\text { density of noncondensable gas, slug } / \mathrm{ft}^{3} \\ \rho_{\text {vap }} & =\text { density of vapor, slug } / \mathrm{ft}^{3}\end{array}$

\section{Introduction}

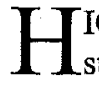
IGH energy cryogenic propellants are being considered for NASA's space exploration program including the stages for Earth departure, Lunar descent, and Lunar ascent. Cryogenic fluid management (CFM) technology and advanced development are essential to making these types of vehicles a reality. NASA and its industrial partners are committed to an advanced development and technology program that will broaden the experience base for the entire CFM community. The high cost of, and limited opportunities for, microgravity experiments have motivated the Marshall Space Flight Center (MSFC) and Boeing team to aggressively explore combinations of ground testing and computational fluid dynamics (CFD) to the greatest extent possible. Here, the overall strategy is to first anchor the CFD models with existing data, then use the models for spacecraft mission simulations to evaluate the effects of acceleration on pressure control thermodynamics. It is believed that the CFD modeling can be used to significantly decrease reliance on costly and infrequent CFM orbital flight experiments.

Of particular interest is the long-term, in-space storage ( $>30$ days) of several cryogenic liquids including liquid hydrogen $\left(\mathrm{LH}_{2}\right)$, liquid oxygen $\left(\mathrm{LO}_{2}\right)$, liquid methane $\left(\mathrm{LCH}_{4}\right)$, and liquid nitrogen $\left(\mathrm{LN}_{2}\right)$. Tanks containing these cryogenic liquids can have ullage gas regions consisting of each liquid's vapor $\left(\mathrm{GH}_{2}, \mathrm{GO}_{2}, \mathrm{GCH}_{4}\right.$, and $\left.\mathrm{GN}_{2}\right)$ or a mixture of vapor with a second gas that is noncondensable at tank temperatures such as gaseous helium (GHe). Heat enters each tank's fluids through the tank walls and through attached plumbing. Advanced CFM technologies such as a spray bar thermodynamic vent system (TVS) enable long term cryogenic storage and propulsion through reliable control of tank pressure with minimal fluid loss. The state of the art for cryogenic upper stage tank pressure control is to settle the propellant and vent until the pressure reaches the desired operating pressure. The auxiliary. systems required for propellant settling incur weight penalties in the form of both propellant and hardware. Newer designs such as the spray bar TVS tank can reduce overall spacecraft mass by decreasing the amount of propellant and hardware needed for long space flights.

The first step towards the accurate simulation of spacecraft cryogenic tanks is the development of validated models using physical test data. Recently, a FLOW-3D* based approach for $\mathrm{LH}_{2}$ tank pressurization was quantitatively verified with data from the Saturn SIV-B stage flown in $1966 .{ }^{1}$ In the present work a similar method is now applied to normal-gravity ground tests of cryogenic tanks with thermodynamic vent systems. Many cryogenic tests have been conducted at the NASA MSFC Multipurpose Hydrogen Test Bed (MHTB). ${ }^{2}$ Two specific spray bar TVS test cases, one $\mathrm{LH}_{2}$ and one $\mathrm{LN}_{2}$, are selected for simulation with CFD. The model results are then compared to the test data to assess the accuracy of the developed FLOW-3D software and modeling techniques.

\section{Approach}

Two physical tests are modeled with the FLOW-3D software where a customized version is used to include the two-phase effects with an ullage gas mixture. A summary of the FLOW-3D theory is presented below followed by a description of each simulation.

\section{A. FLOW-3D Theory}

The standard version of FLOW-3D contains a phase change model to predict the interactions of evaporation and condensation at liquid-gas interfaces. The model assumes that the gas phase is composed entirely of the vapor of the liquid. Conservation of both mass and momentum are maintained on both sides of the interface. The mass transfer rate between the liquid and vapor phases is predicted to be

\footnotetext{
*FLOW-3D is a registered trademark of Flow Science, Inc. of Santa Fe, New Mexico, USA.
} 


$$
q=C \sqrt{\frac{M_{v a p}}{2 \pi R T}}\left(P^{s a t}-P\right)
$$

where $q$ is the mass transfer rate, in units of mass per unit area per unit time, $M_{v a p}$ is the molecular weight of the vapor, $R$ is the universal gas constant, $T$ is the local temperature of the liquid at the interface, $P$ is the local pressure in the vapor phase, and $P^{\text {sat }}$ is the saturation pressure of the liquid., ${ }^{3,4}$ Equation 1 merely states that, for a given temperature, the mass transfer rate is linearly dependent on the difference between the equilibrium and actual vapor pressures. Note that at higher temperatures, the rate is reduced due to the larger gas volume and thus resistance to mass transfer. The rate coefficient $C$ controls the rate of mass transfer at the interface; this is needed for cases when there is not sufficient grid resolution to predict the kinetics of the phase change at the interface. $P^{s a t}$ is defined from the Clausius-Clapeyron equation. ${ }^{3}$

$$
P^{\text {sat }}=P_{c} \exp \left[-\frac{\Delta H_{v}}{(\gamma-1) c_{v}^{v a p}}\left(\frac{1}{T}-\frac{1}{T_{c}}\right)\right]
$$

$\left(T_{c}, P_{c}\right)$ is a point on the saturation curve, $\gamma$ is the ratio of the heat capacity of the vapor at constant pressure to its heat capacity at constant volume, $c_{v}{ }^{v a p}$, and $\Delta H_{v}$ is its latent heat of vaporization.

FLOW-3D has been customized to include the effects of an additional component in the gas phase. This component is assumed to be non-condensable and is thus not involved in mass transfer at the interface, but it does affect the mass transfer rate of the vapor component.

$$
q^{\prime}=\frac{C}{\sqrt{2 \pi R^{\prime} T}}\left(P^{s a t}-P_{v a p}\right)
$$

Equation 3 differs from Eq. 1 with the addition of a mean gas constant, $\overline{R^{\prime}}$, and the partial pressure of the vapor in the gas phase, $P_{\text {vap. }} \cdot \overline{R^{\prime}}$ is computed from

$$
\overline{R^{\prime}}=R \frac{\rho_{v a p} / M_{v a p}+\rho_{n c} M_{n c}}{\rho_{g}},
$$

where $M_{n c}$ is the molecular weight of the non-condensable gas, $\rho_{v a p}$ and $\rho_{n c}$ are the densities of the vapor and noncondensable gas, and $\rho_{g}$ is the gas mixture density. The partial pressure of the vapor is

$$
P_{v a p}=\rho_{v a p} R T / M_{v a p}
$$

and the non-condensable gas is transported throughout the gas mixture,

$$
\frac{\partial \rho_{n c}}{\partial t}+\nabla \cdot\left(\rho_{n c} \mathbf{v}\right)=D_{n c} \nabla^{2} \rho_{n c}
$$

where $\mathbf{v}$ is the gas mixture velocity and $D_{n c}$ is the molecular diffusion coefficient. Eq. 6 is solved throughout the gas phase, in conjunction with equations of mass and momentum conservation which solve for the gas density $\rho_{g}$. The vapor concentration $\rho_{v a p}$ is then solved from the difference $\rho_{g}-\rho_{n c}$.

\section{B. Hydrogen Tank Model}

The $10-\mathrm{ft}$ diameter, 10 - $\mathrm{ft}$ long, MHTB tank is modeled with 2460 -cell axisymmetric computational mesh as illustrated in Fig. 1. A spray bar is located at the center of the tank where it is modeled as a 1-inch diameter cylinder that runs from the bottom of the tank to the top. An annular inlet from a radius of $1.0 \mathrm{ft}$ to $1.4 \mathrm{ft}$ is used to drain liquid from the tank. Further details of the MHTB test apparatus can be found in Ref. 2. The initial liquid level is $5 \mathrm{ft}$ from the bottom of the tank and so the tank is approximately $50 \%$ filled with LH2. The ullage space above the liquid 
contains a GH2/GHe gas mixture initially at 24 psia; $4.3 \mathrm{lbm}$ of GHe is present in the ullage. The bulk LH2 is initially near $39.5 \mathrm{R}$ and the ullage is thermally stratified. A heat leak of $70 \mathrm{~W}$ is supplied to the fluids via a distributed power boundary condition where $60.4 \mathrm{~W}$ flows from the tank cylinder and aft dome into the liquid, $4.9 \mathrm{~W}$ flows into the lower ullage region from the free surface to $3.3 \mathrm{ft}$ above it, and $4.73 \mathrm{~W}$ flows into the remaining upper ullage region. The spray bar, TVS inlet, and flange recess at the top of the tank are all adiabatic in the model.

Model operation mimics a cryogenic tank pressure control cycle on a spacecraft as does the physical test. It begins with setting up the initial condition and followed by the pressurization phase. During pressurization heat is supplied to the tank while the TVS spray is off. Heat flows into the fluid domains as specified by the above power boundary conditions and thus heat transfer is independent of local fluid conditions. After the tank pressure reaches a specified value (25 psia for the LH2 model), then the spray bar TVS is activated where cooler liquid is injected in a spray pattern throughout the tank. At the same time liquid is removed from the annular inlet at the bottom of the tank. The $30 \mathrm{gpm}$ spray pattern consists of 45 individual mass sources uniformly distributed in the fluid domain where each source injects mass at 35.7R. This is an approximation for the radially emitting flow of the spray bar; it allows much coarser grid resolutions to be used in the model and in turn faster run

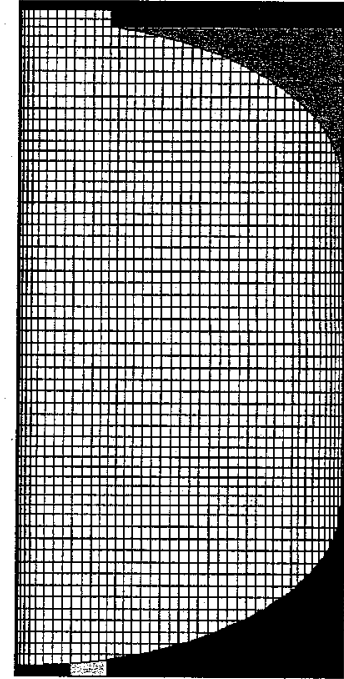

Figure 1 Tank Model times. Once the tank pressure decreases to a specified level ( 24 psia for the LH2 tank model), the TVS spray flow is stopped and the tank begins to pressurize again.

Collected results include ullage pressure history, ullage temperature history, liquid temperature history, temperature contours and velocity distribution. The pressure temperature histories are utilized in the comparison of predictions to test data. Here, the ullage pressure and temperature are compared at sensor 1 (radius $=2.5 \mathrm{ft}$, height $=$ $8.9 \mathrm{ft}$ ) while liquid temperature is compared at sensor 2 (radius $=2.5 \mathrm{ft}$, height $=4.4 \mathrm{ft}$ ).

\section{Nitrogen Tank Model}

The same MHTB test tank is used for the nitrogen testing as the one previously used for hydrogen testing. However, to deliver additional heat to the fluid an electric heater is installed at the bottom of the tank where it is submersed in LN2. The actual heater is a 5/8" diameter cylindrical rod that is offset from the centerline of the tank. The heating element is moved to the centerline of the tank so that it can be modeled with the axisymmetric computational grid and practical run times. Here, the heating element occupies the bottom 1.42 feet of the spray bar in the LN2 tank case. A total of $370 \mathrm{~W}$ of heat are flowed into the LN2 tank where $250 \mathrm{~W}$ are supplied by the heater and $120 \mathrm{~W}$ are input from the tank walls. The $120-\mathrm{W}$ wall heat leak is divided where $76.9 \mathrm{~W}$ flow uniformly into the liquid, $40.4 \mathrm{~W}$ flow into the first $3.29 \mathrm{ft}$ of ullage above the liquid-gas interface, and $2.8 \mathrm{~W}$ flow into the remaining ullage space. As in the LH2 cases the spray bar, TVS inlet, and the top flange recess are all adiabatic in the model.

The same 2460-cell computational mesh is used in the nitrogen model as shown in Fig. 1 . The initial liquid level for the nitrogen case is $5.47 \mathrm{ft}$ from the bottom of the tank which means that the tank is approximately $56 \%$ filled with LN2. The initial ullage pressure is 23 psia and the pressurization phase simulates the rise to 24 psia. Similar to the LH2 case, a 1 psi decrease is modeled with the TVS spray flow where the end pressure is 23 psia. The total LN2 flow rate is $30 \mathrm{gpm}$ that is distributed among 45 evenly spaced sources in the tank. LN2 spray temperature is $138.7 \mathrm{R}$ in the simulation. Following depressurization from the TVS phase, the tank repressurizes to 24 psia. Recorded results for the nitrogen model include ullage pressure history, ullage temperature history, liquid temperature history, temperature contours and velocity distribution. The same pressure and temperature sensors are used for the nitrogen model and test comparison as those used in the hydrogen model.

\section{Results \& Discussion}

The results for both cryogenic simulations are described below and include the ullage pressures, ullage temperatures, liquid temperatures, and contour plots showing the temperature and velocity fields.

\section{A. Hydrogen Tank Results}

As shown in Fig. 2 the hydrogen model approximates the steady linear portion of the pressure rise rate curve quite well for the two pressurization cycles simulated. For the first cycle the model determines $0.63 \mathrm{psi} / \mathrm{hr}$ versus a measured $0.55 \mathrm{psi} / \mathrm{hr}(14.5 \%$ error) and for the second cycle the model yields $0.60 \mathrm{psi} / \mathrm{hr}$ versus a measured 0.53 
$\mathrm{psi} / \mathrm{hr}$ (13.2\% error). When considering the average pressurization rate over the one psi range from 24 to 25 , the model predicts $0.66 \mathrm{psi} / \mathrm{hr}$ versus $0.89 \mathrm{psi} / \mathrm{hr}(25.8 \%$ error) for the first cycle. The rapid initial pressure rise immediately following a TVS cycle is suspected to be sensitive to the actual wall temperature during the tests which influences the heat transfer rate from the wall to fluid. In the present constant heat leak model the heat transfer is fixed and not influenced by local wall or fluid temperature. Accordingly, the rapid initial transient is not captured in the model. During TVS spray the model predicts a depressurization rate of $14.1 \mathrm{psi} / \mathrm{hr}$ compared to $7.5 \mathrm{psi} / \mathrm{hr}$ ( $46.8 \%$ error) measured in the test. This is for a $30 \mathrm{gpm}$ volumetric spray flow rate at a uniform temperature of $35.7 \mathrm{R}$. Physically, the spray bar jet temperature can not be constant as the TVS fluid is moving through the spray bar tubes warming up as it moves towards the top of the tank where the gas is warmest. However, without accurate knowledge of the initial jet temperatures versus distance along the spray bar, a single constant value slightly below the saturation temperature is selected. This temperature is more representative of a TVS jet in the upper ullage region than in the lower ullage or liquid regions since cooling of the warmer gas is more effective in reducing tank pressure.

Temperature history results for the hydrogen simulation are shown in Figs. 3 and 4. The calculated temperature trends for both the liquid and gas phases generally mimic the test data. Here, the predicted liquid temperature at sensor 2 is within $0.2 \mathrm{R}$ of the test data $(\sim 0.5 \%$ error) for the complete test. The predicted and recorded gas temperatures at sensor 1 are within about $2 \mathrm{R}$ for the duration of the simulation $(\sim 4.8 \%$ error $)$. It is noted that the temperatures recorded during the MHTB testing indicate an inverted temperature profile at times where the gas is colder than the liquid; this could be indicative of sensor variation.

The temperature and velocity fields are indicated in Fig. 5 where the tank is shown during pressurization, TVS spray, and repressurization. In Fig. 5a the LH2 tank is shown while pressurizing where the liquid is relatively colder than the gas and the gas is thermally stratified by a few tenths of a degree Rankine. In Fig. $5 b$ the LH2 TVS is shown in operation where fluid from the spray is dropping into the liquid region. Nearest the spray bar where radial spray mass flux is greatest, little of the liquid is vaporized and thus falls downward into the liquid. During the TVS spray phase, ullage stratification has decreased to a few hundredths of a degree R. Some liquid can be seen dripping down the tank walls also and elsewhere in the ullage region. After the TVS spray phase another pressurization cycle is simulated as illustrated in Fig. 5c. Once again pronounced thermal boundary layers can be seen at the tank walls while warm gas is being deposited at the top of the tank. The hydrogen simulated pressurization, TVS operation, and repressurization required 91 hours to run on a single Intel Xeon $3.0 \mathrm{GHz}$ processor running Microsoft Windows 2003 Server Edition operating system.

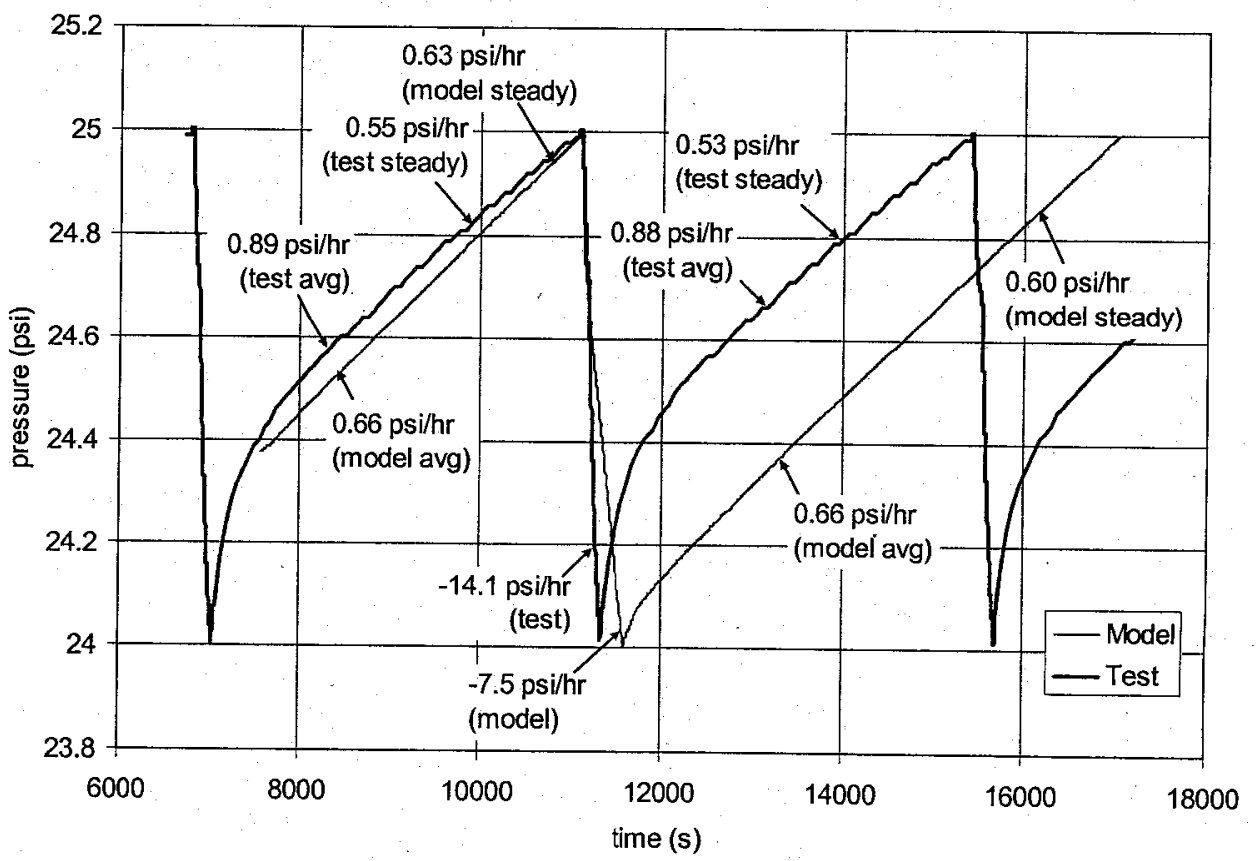

Figure 2 Hydrogen Tank Ullage Gas Pressure History 


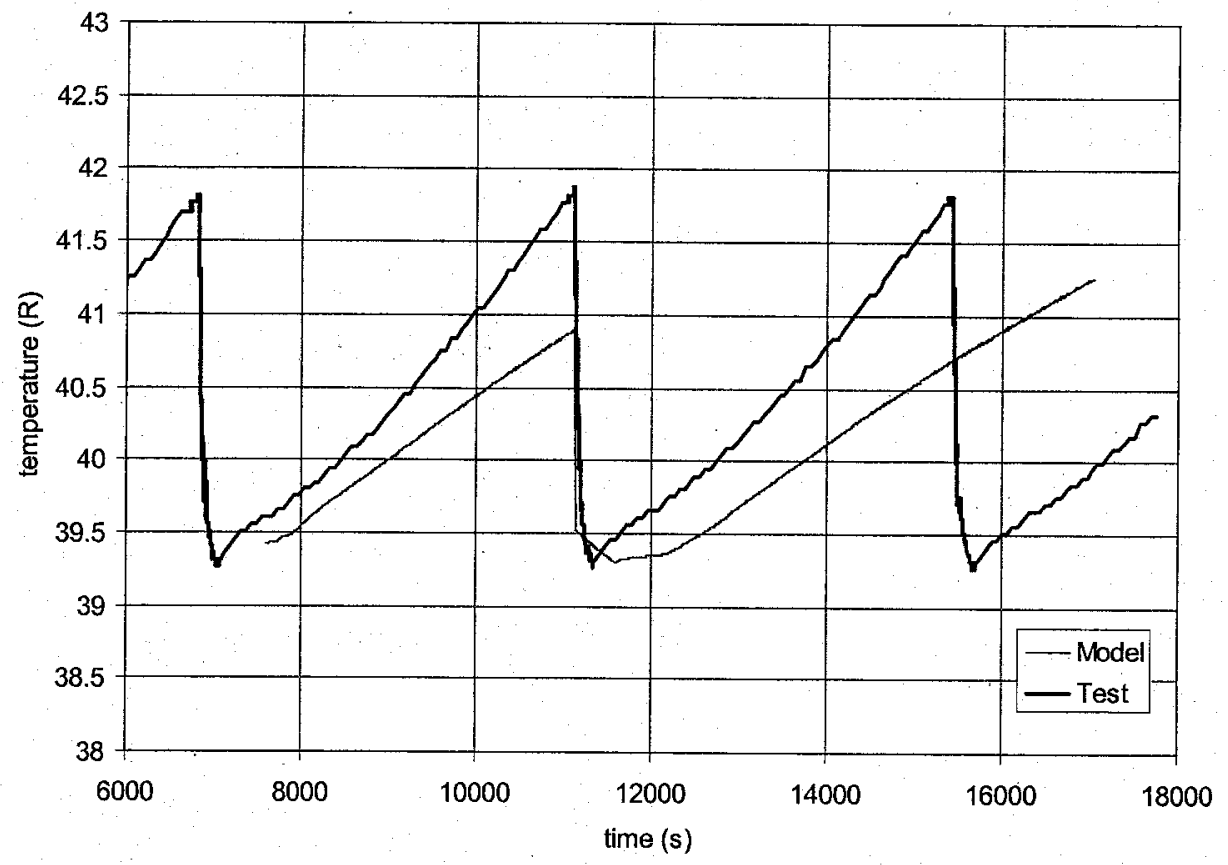

Figure 3 Hydrogen Tank Ullage Gas Temperature History

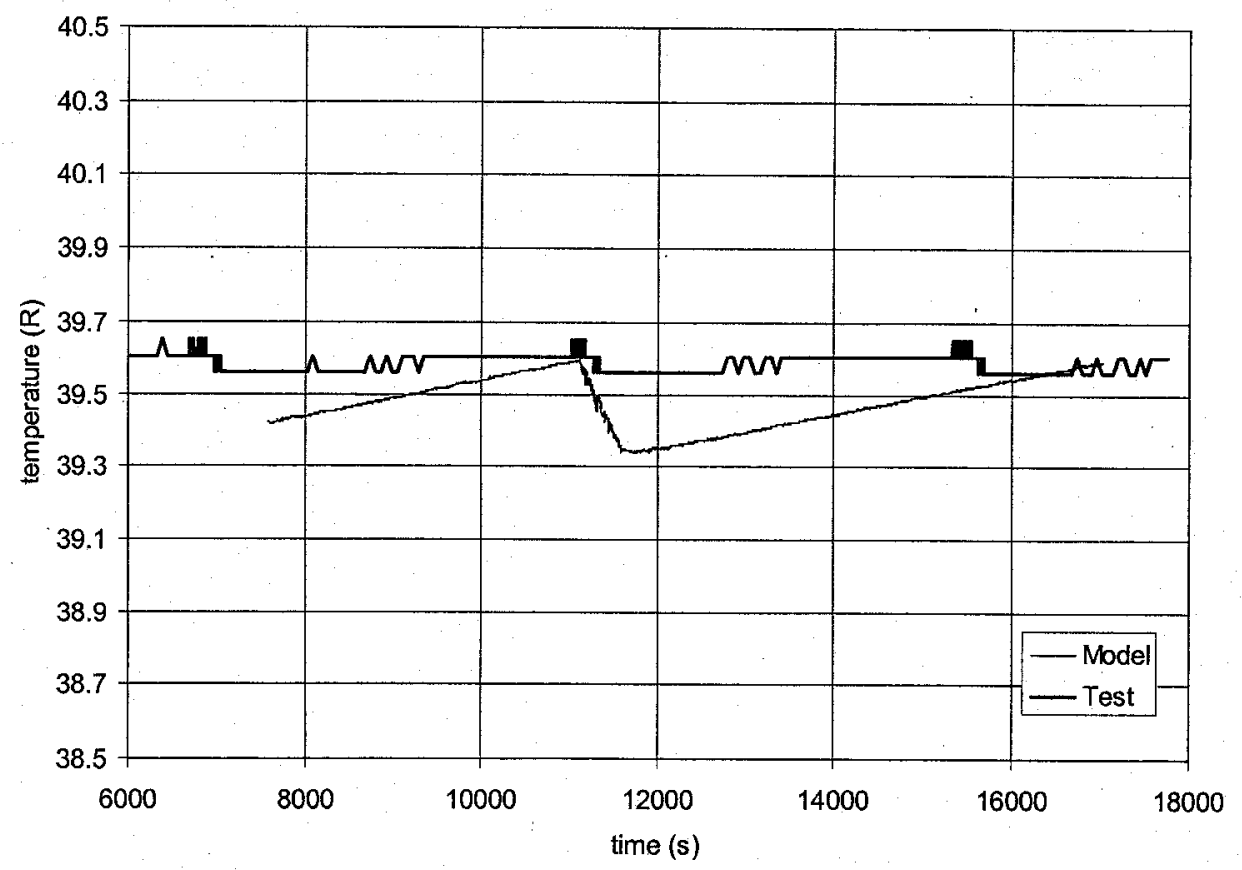

Figure 4 Hydrogen Tank Liquid Temperature History 


\section{B. Nitrogen Tank Results}

The nitrogen tank model represents the tank pressurization rate well as indicted in the model versus test comparison in Fig. 6. Unlike the LH2 test the LN2 test does not show as pronounced linear region with a severe of a change in pressurization rate from the beginning to the end of a cycle. Accordingly, only average pressurization rates are compared where the model yields $0.33 \mathrm{psi} / \mathrm{hr}$ versus a measured $0.30 \mathrm{psi} / \mathrm{hr}$ (10\% error) for the first pressurization cycle simulated and $0.37 \mathrm{psi} / \mathrm{hr}$ versus a test value of $0.30 \mathrm{psi} / \mathrm{hr}(23.3 \%$ error $)$. Here in the nitrogen model also, the TVS spray model has produced reasonable estimates for the cooling and depressurization performance of the actual TVS. For the $30-\mathrm{gpm}$, 138.7-R spray flow the model predicts a depressurization rate of $2.2 \mathrm{psi} / \mathrm{hr}$ versus $1.6 \mathrm{psi} / \mathrm{hr}$ (37.5\% error) in the test.

As shown in Figs. 7 and 8 the temperature predictions also follow the test data trends although there is about a $1.5 \mathrm{R}(\sim 1.1 \%$ error) offset in the liquid temperature comparison as measured at sensor 2 and the ullage gas is initially warmer as measured at sensor 1 . The predicted ullage gas temperature on the first pressurization cycle is 6 $\mathrm{R}$ warmer than the test data $(150 \mathrm{R}$ vs. $144 \mathrm{R}, \sim 4.2 \%$ error), however, the calculated and measured temperatures come closer together in the second cycle where the differences are no more than $1 \mathrm{R}(\sim 0.7 \%$ error $)$.

In the temperature contour and velocity vector plots illustrated in Fig. 9 the pressurization, TVS spray, and repressurization effects can be observed. In Fig. 9a the tank of LN2 is highly stratified in the top part of the tank. Thin thermal boundary layers can be noticed in the ullage region (just below the yellow contour) that continuously supply warm gas to the upper tank. During this pressurization phase the ullage is stratified by about $10 \mathrm{R}$. In Fig. $9 \mathrm{~b}$ the TVS spray is shown cooling and depressurizing the tank. Downward motion near the spray bar also occurs in the nitrogen case as it did in the hydrogen case where unvaporized liquid falls into the tank. At the time shown in Fig. $9 \mathrm{~b}$ the TVS spray has decreased the ullage gas thermal stratification to less than $0.5 \mathrm{R}$. The initial transient repressurization phase is illustrated in Fig. $9 \mathrm{c}$ where the mass momentum boundary layers due to natural convection reform and the tank begins to pressurize and thermally stratify. The nitrogen model simulated pressurization, TVS operation, and repressurization required 240 hours to run on a single Intel Xeon $2.8 \mathrm{GHz}$ processor running Microsoft Windows XP Professional operating system.

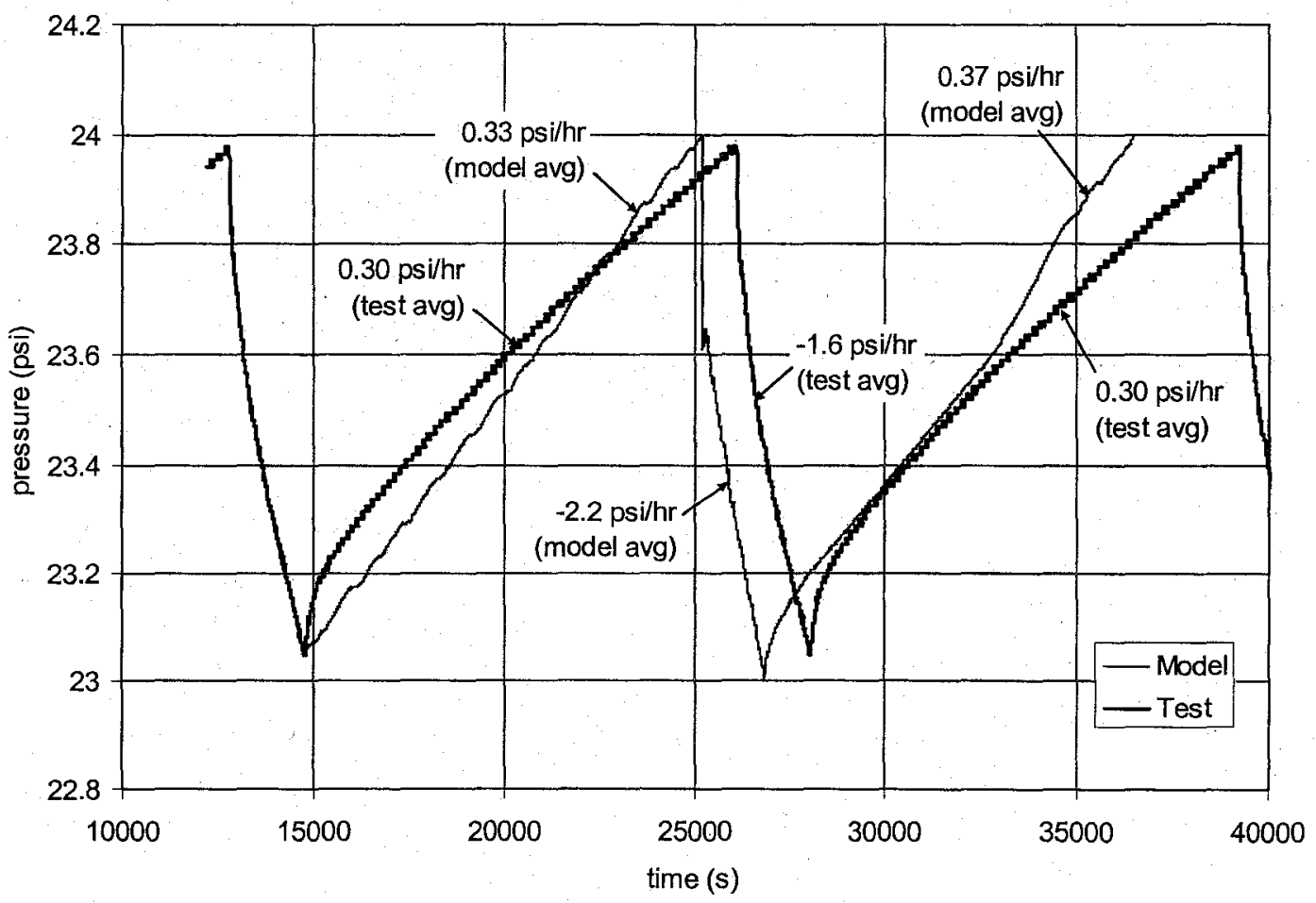

Figure 6 Nitrogen Tank Ullage Gas Pressure History 


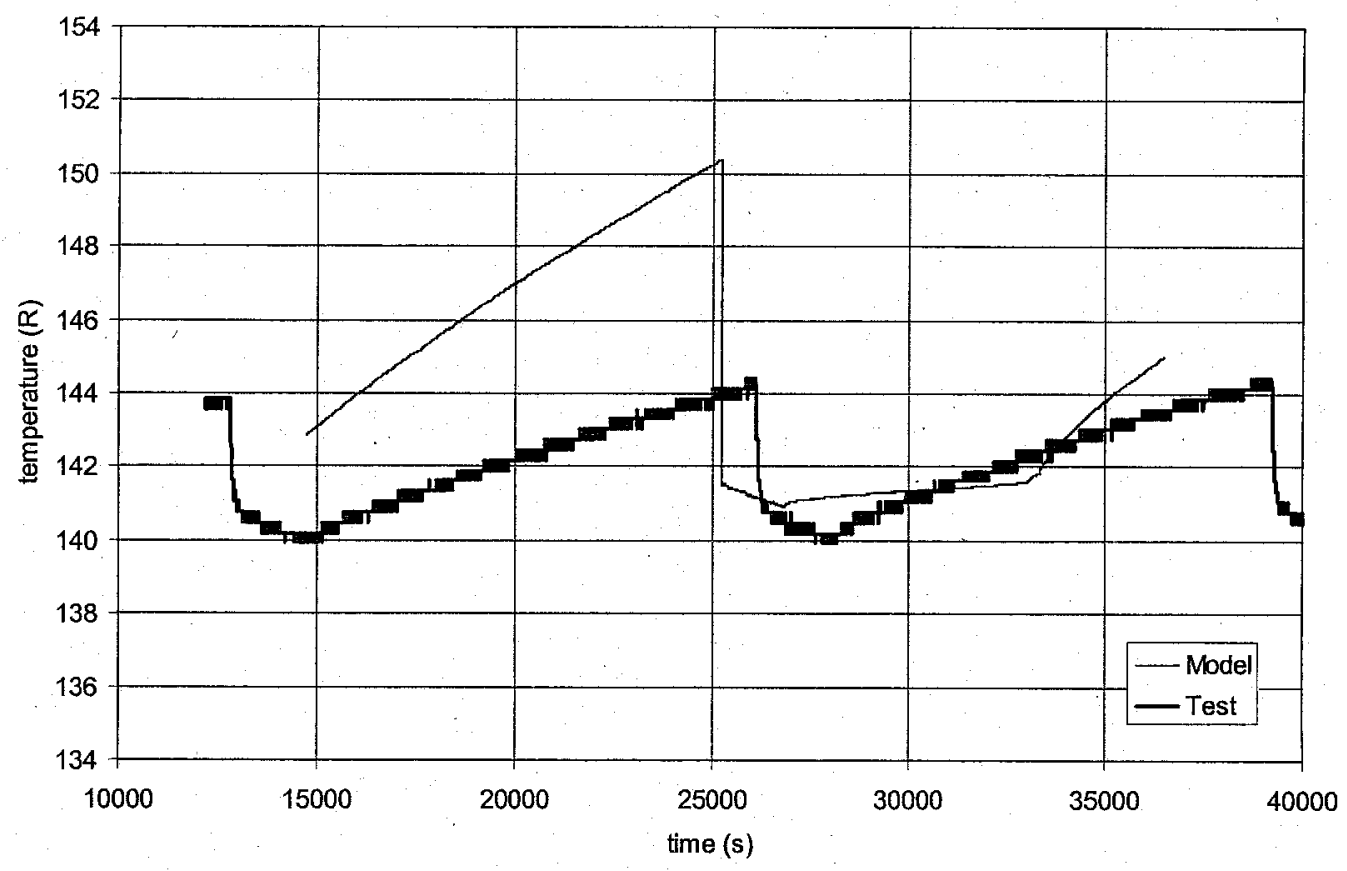

Figure 7 Nitrogen Tank Ullage Gas Temperature History

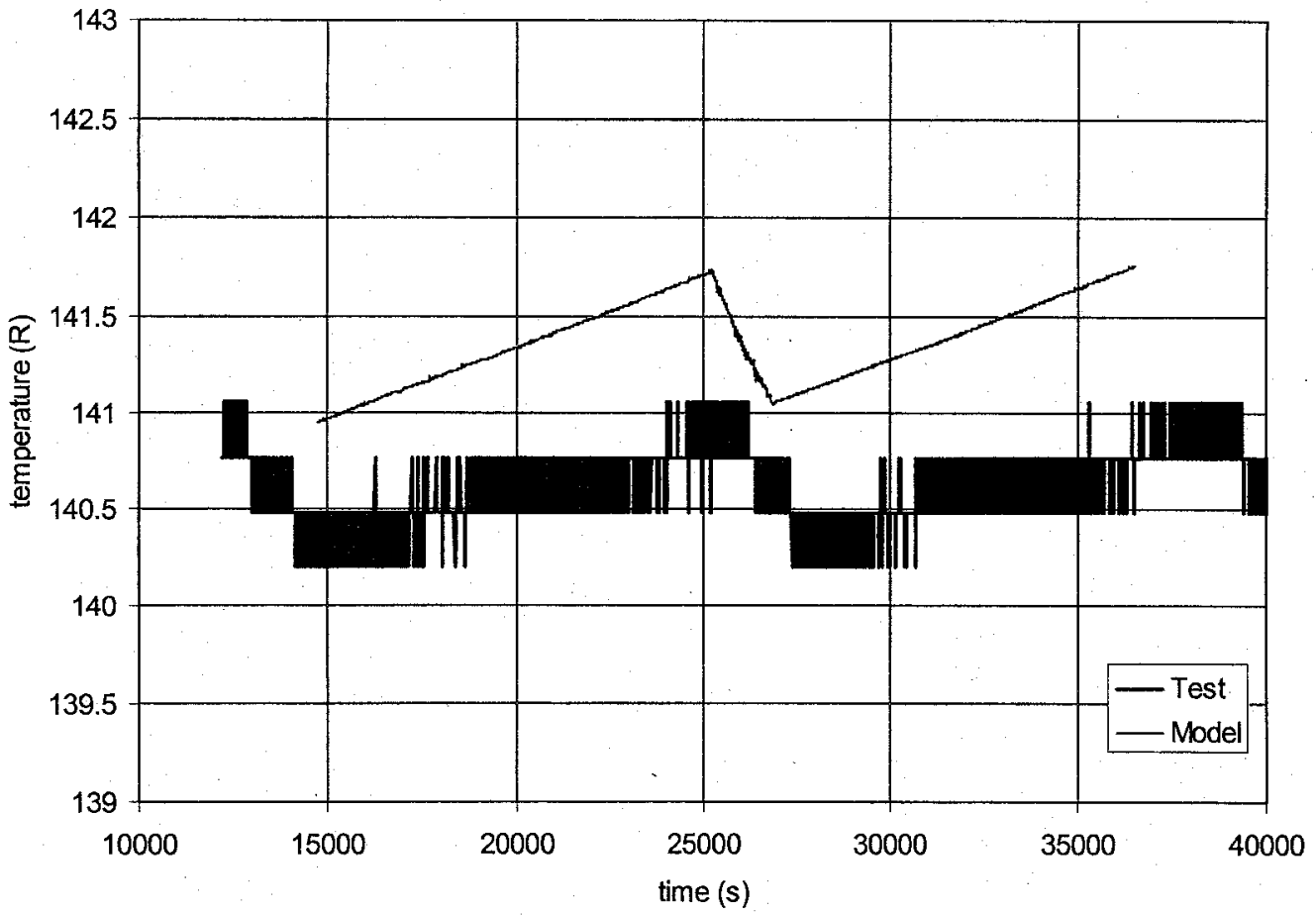

Figure 8 Nitrogen Tank Liquid Temperature History 


\section{Conclusion}

Two FLOW-3D based models of the MHTB tests have been quantitatively validated. Overall the accuracy of the average pressurization rate prediction is within $26 \%$ for all cases. However, when the steady state portion of the LH2 tests is considered without the initial transient the predicted pressurization rates within $15 \%$ of the test data can be achieved. The TVS spray model yields depressurization rate predictions that are within about $50 \%$ of the measured rates. The liquid and gas temperature data generally follow the trends of the test data, although some offsets exist and the predicted gas temperatures for the LN2 cases are warmer than the test data indicates. Although the local predicted temperatures may not precisely match the test data, the approximations are close enough to yield good estimates of the pressurization rate. This work further expands the quantitative validation database for the FLOW-3D based cryogenic simulation tools that can be used to aid aerospace design and analysis.

During the Apollo and Space Shuttle programs, the design activity was performed based on solid engineering principles and techniques but generally with hand analysis, slide rules, automatic calculators and simple computational codes assisted by batch computer processing. Now engineering tools for analysis and design are available for use on desktops and workstations with relatively quick answers to complex, posed design problems. This rapidity in the development of key design information has accelerated the design activity to the point where preliminary designs can be accomplished in a very short period of time compared to the Apollo and Space Shuttle era. The increased fidelity of the design information has lowered the cost and schedule risks associated with extremely complex and one of a kind engineering feats. However the process of proving that the design is adequate for all environments has still relied heavily on the performance of ground testing supplemented where possible with orbital testing. With the advent of modern computational design tools applying CFD to internal flow dynamic systems, the requirement to test every aspect of the applicable environment is no longer required. As with the CFD tools used to assess the aerodynamics of supersonic to hypersonic flight with anchor runs using the wind tunnel, so it can now be with the new CFD tools for analysis of complex spacecraft propellant systems with appropriate anchoring using ground testing.

\section{Acknowledgments}

This work was supported by the NASA Marshall Space Flight Center under the Pressure Control Data Correlation contract NNM05AB18C.

\section{References}

${ }^{1}$ Grayson, G.D. and Lopez, A., "Cryogenic Tank Modeling for the Saturn AS-203 Experiment," AIAA Paper 2006-5258, 09 March 2006.

${ }^{2}$ Hastings, L.J., Flachbart, R.H., Martin, J.J., Hedayat, A., Fazah, M., Lak, T., Nguyen, H., and Bailey, J.W., "Spray Bar Zero-Gravity Vent System for On-Orbit Liquid Hydrogen Storage," NASA TM-2003-212926, October 2003.

${ }^{3}$ Hirt, C. W., "Modeling Phase Change and Homogenous Bubbles," Flow Science Technical Note FSI-01TN57, 2001.

${ }^{4}$ Smith, J. M., and Van Ness, H. C., Introduction to Chemical Engineering Thermodynamics, 4th ed., McGrawHill, New York, 1987, pp. 181-182. 


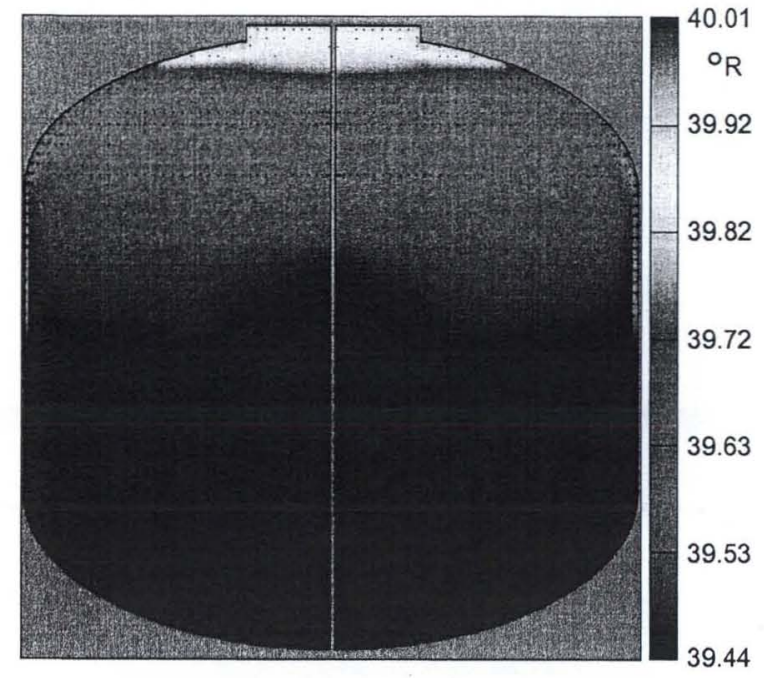

a) $t=8140 \mathrm{~s}, \mathrm{Vmax}=0.526 \mathrm{ft} / \mathrm{s}$

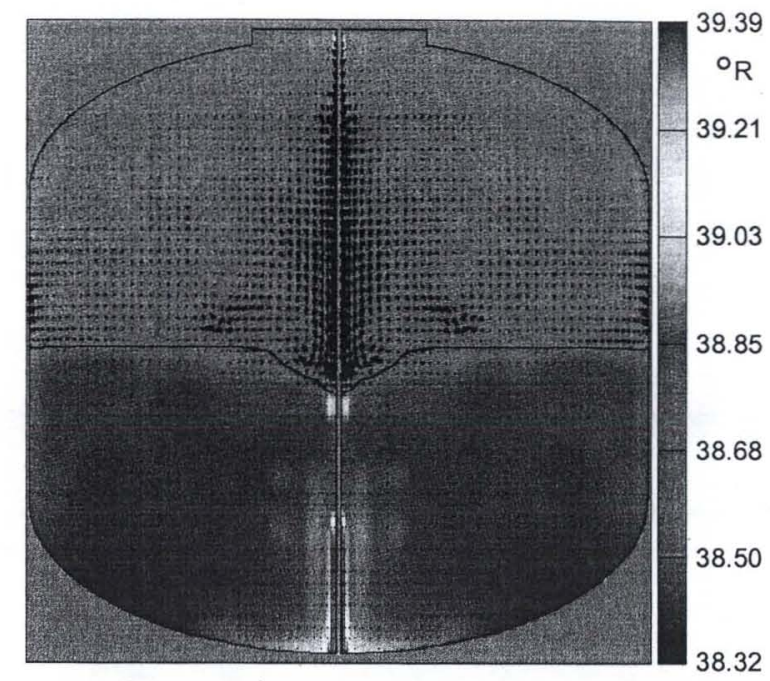

b) $\mathrm{t}=11600 \mathrm{~s}, \mathrm{~V} \max =12.2 \mathrm{ft} / \mathrm{s}$

Figure 5 Hydrogen Tank Temperature and Velocity Field Results

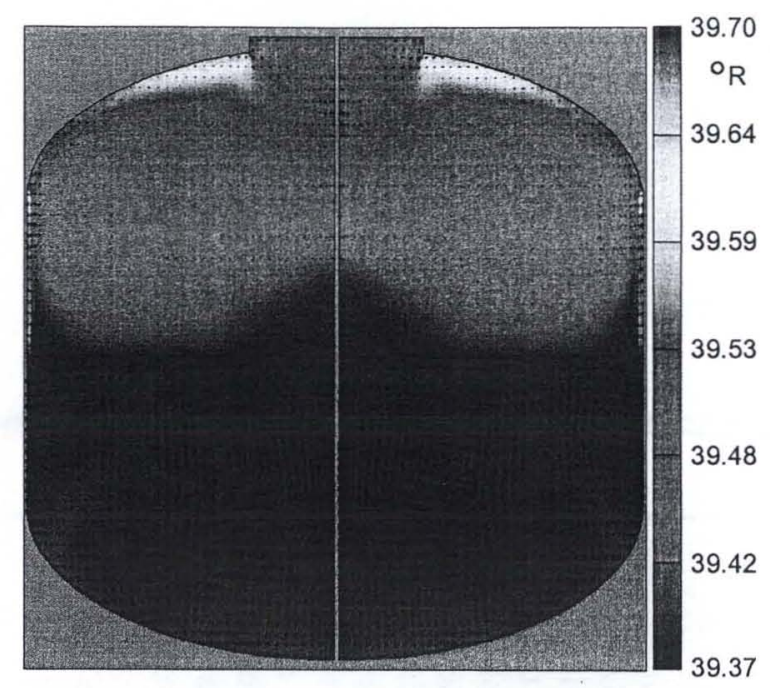

c) $\mathrm{t}=12620 \mathrm{~s}, \mathrm{~V} \max =0.494 \mathrm{ft} / \mathrm{s}$

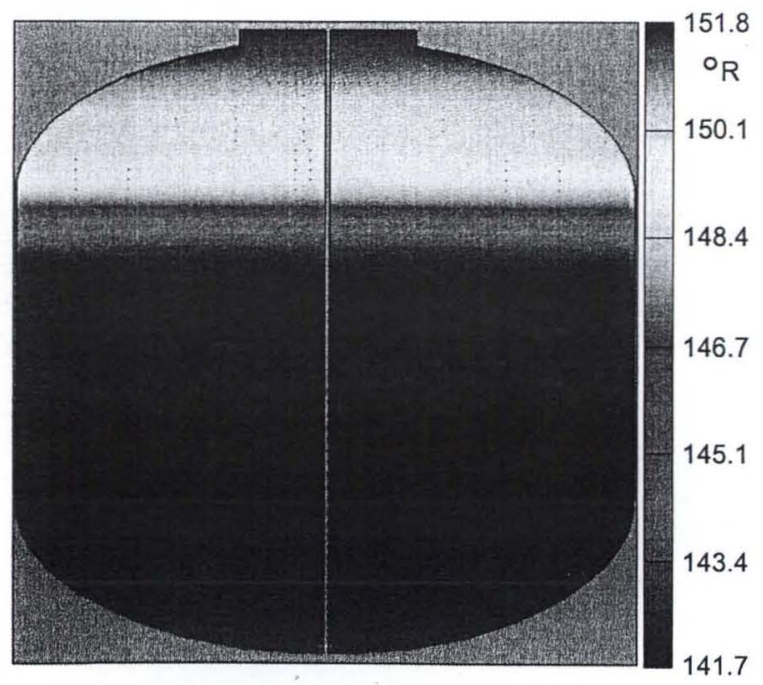

a) $\mathrm{t}=25230 \mathrm{~s}, \mathrm{Vmax}=0.915 \mathrm{ft} / \mathrm{s}$

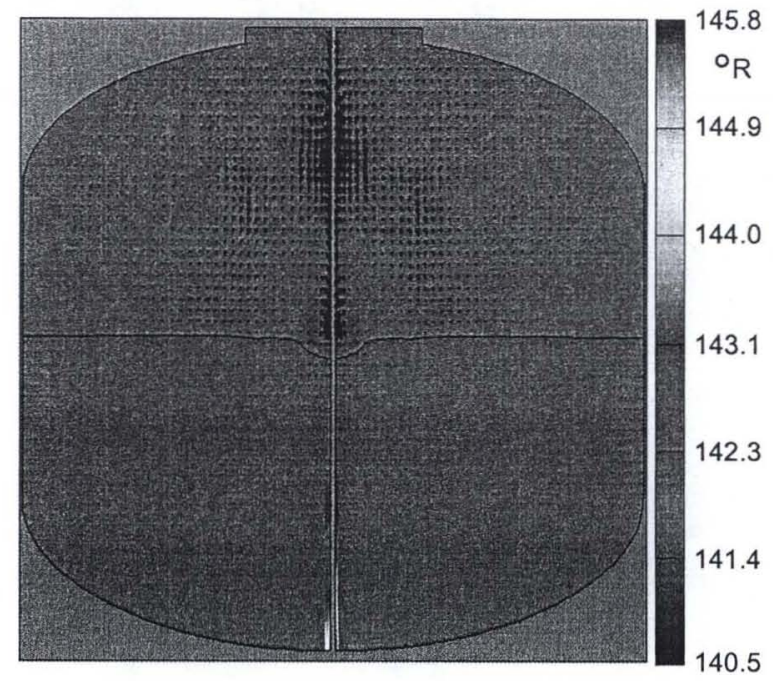

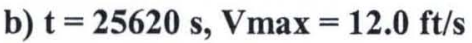

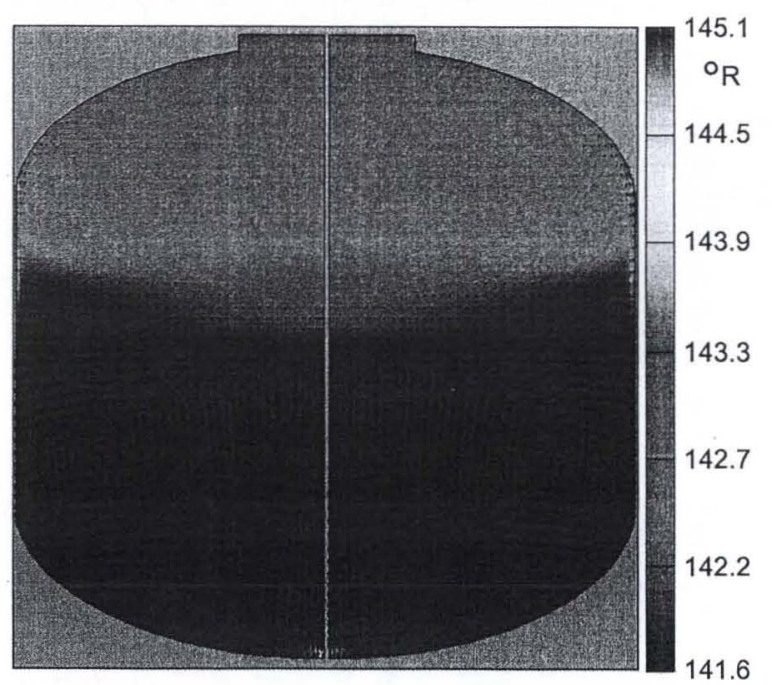

c) $\mathrm{t}=34260 \mathrm{~s}, \mathrm{Vmax}=0.508 \mathrm{ft} / \mathrm{s}$

Figure 9 Nitrogen Tank Temperature and Velocity Field Results 